\title{
PENGOLAHAN TANAMAN OBAT TRADISIONAL: BAWANG DAYAK DAN JAHE MERAH
}

\author{
Ir. Nursiah, M.P., Desy Natalia Koroh, S. Hut, M. Si., Ir. Sarinah, M.P \\ Dosen Jurusan Kehutanan Fakultas Pertanian Universitas Palangka Raya \\ E-mail: nursiahyadi@gmail.com
}

\begin{abstract}
ABSTRAK
Masyarakat kota Palangka Raya dan sekitarnya masih mempunyai budaya minum obat tradisional terutama bawang dayak dan jahe karena masyarakat sudah mengetahui khasiat dari bawang dayak dan jahe tersebut. Agar produk jamu dapat diterima masyarakat luas maka salah satu faktor penting adalah cara pengolahannya dan cara pengemasan. Kemasan juga bisa berfungsi sebagai media promosi karena bisa menarik perhatian dengan adanya gambar, tulisan, warna dan penampilan. Tujuan kegiatan pengabdian pada masyarakat ini adalah memberikan pengetahuan dan ketrampilan tentang pengolahan umbi bawang dayak, dan rimpang jahe berbentuk simplisia, bubuk dan instan serta mengenalkan model dan cara pengemasan sehingga dapat menambah nilai jual produk jamu tersebut. Metode yang digunakan: ceramah, diskusi dan pembagian modul pelatihan dan pelaksanaan praktek langsung cara pembuatan obat tradisional yaitu pengolahan umbi bawang dayak, dan rimpang jahe merah berbentuk simplisia, bubuk dan instan dan cara pengemasan. Hasil yang diperoleh adalah kelompok mitra dapat meningkatkan nilai jual tanaman obat tradisional, memperoleh pengetahuan, dan mampu mengolah tanaman obat tradisional umbi bawang dayak dan rimpang jahe merah berbentuk simplisia, bubuk dan instan yang baik (CPOB), serta cara pengemasan dan juga dapat memberikan manfaat untuk kesehatan dan mengurangi biaya untuk berobat dan hasilnya juga dapat menambah pendapatan apabila dikembangkan secara luas dengan kemasan yang menarik.
\end{abstract}

Kata kunci: Bawang dayak, Jahe merah, Simplisia, Bubuk, Instan, Kemasan

\section{PENDAHULUAN}

Riset kesehatan Dasar (Riskesdas) tahun 2010 (Litbang Depkes RI tahun 2014), menunjukkan bahwa 50\% penduduk Indonesia menggunakan jamu baik untuk menjaga kesehatan maupun untuk pengobatan karena sakit. Data Riskesdas ini menunjukkan bahwa, jamu sebagai bagian dari pengobatan tradisional, telah diterima oleh masyarakat Indonesia. Oleh karena itu, jamu dan obat-obatan tradisional perlu didorong untuk menjadi salah satu pilihan pengobatan dan pencegahan penyakit. Jamu dan obat-obatan tradisional harus didorong pula untuk menjadi komoditi unggulan yang dapat memberikan sumbangan positif bagi meningkatkan pertumbuhan ekonomi masyarakat

Sebagian besar penjual obat tradisional di Pasar Kahayan dan masyarakat Kota Palangkaraya menjual obat tradisionalnya masih dalam bentuk umbi atau rimpang nya saja karena keterbatasan pengetahuan pedagang dan masyarakat tersebut tentang cara pengolahan obat tradisional sehingga harga jualnya pun lebih rendah dibandingkan sesudah berupa produk jamu berupa bubuk atau instan.

Permasalahan kaum perempuan yang berprofesi pedagang obat tradisional dan ibu rumah tangga yang berdomisili di jalan Mendawai Sosial dan Flamboyan Bawah merupakan daerah yang padat penduduk dan kondisi ekonomi kelompok mitra masih rendah, Kelompok Mitra rata-rata belum mengetahui cara pengolahan simplisia, bubuk, dan instan umbi bawang dayak, dan rimpang jahe, ini merupakan pengetahuan yang baru bagi kelompok mitra. Masyarakat belum mengetahui cara pengemasan yang baik, menarik dan bernilai jual. Oleh karena itu diperlukan suatu informasi dan pelatihan tentang pengolahan umbi bawang dayak, dan rimpang jahe berbentuk simplisia, bubuk dan instan

Tujuan pengabdian kepada masyarakat ini adalah adalah memberikan pengetahuan dan keterampilan tentang pengolahan tanaman obat, berupa simplisia, bubuk dan instan, mendorong jiwa wirausaha kaum Ibu di kawasan tersebut dengan memberi pengetahuan cara pengemasan produk simplisia, bubuk dan instan yang bahan kemasan yang sesuai produk sehingga tampilannya menarik benilai jual tinggi .

\section{METODE PELAKSANAAN}

Metode dan langkah-langkah yang akan dilakukan adalah sebagai berikut:

1. Ceramah, diskusi dan pembagian materi pelatihan cara pengolahan simplisia, bubuk, dan instan dari umbi bawang dayak dan rimpang jahe dan juga cara pengemasan yang baik dan menarik.

2. Pelatihan dengan mempraktekkan langsung cara pengolahan simplisia, bubuk dan instan dari umbi bawang dayak dan rimpang jahe. Dilanjutkan cara pengemasannya bahan dan desain labelnya.

Tempat pelaksanaan kegiatan pelatihan di Jalan Mendawai Sosial Kelurahan Palangka Kecamatan Jekan Raya, dan di 
Jalan Flamboyan Bawah Kelurahan Pahandut Kota Palangka Raya. Peralatan yang digunakan: blender, pisau stainles, ayakan/saringan 50-60 mesh, nyiru, baskom plastik, talenan, spatula kayu, timbangan dan hand sealer/alat perekat plastik. Bahan yang digunakan umbi bawang dayak, rimpang jahe merah, dan plastik pengemas/kapsul. Peserta dibuat 2 (dua) kelompok, masing-masing beranggotakan 10 orang, setelah pelatihan akan dilakukan pembinaan dua bulan.

\section{HASIL DAN PEMBAHASAN}

Pertama-tama Tim pelaksana memberikan materi pelatihan dan penyuluhan tentang manfaat dan khasiat tanaman obat tradisional terutama bawang dayak dan jahe dan kandungan fitokimianya dan juga cara pengolahan obat tradisional berupa simplisia, bubuk, dan instan. Selanjutnya memberikan materi pelatihan dan penyuluhan adalah cara pengolahan tanaman obat tradisional berupa simplisia, bubuk, dan instan dan cara pengemasan yang lebih modern sehingga dapat meningkatkan nilai jual yang lebih tinggi. Selanjutnya dilaksanakan praktek langsung pengolahan tanaman obat tradisional berupa simplisia, bubuk, dan instan sampai mengemas hasil dari produk tersebut. Tahapan-tahapan pengolahan tanaman obat adalah sebagai berikut:

\section{a. Cara Pembuatan Jahe Merah Instan}

Jahe dikupas, dicuci, dipotong tipis/dirajang kemudian diblender, ditambahkan air bersih komposisi $1 \mathrm{~kg}$ jahe + 2 liter air. Kemudian disaring sehingga terpisah antara sari rimpang dengan ampasnya, selanjutnya ampas dibuang. Sari rimpang direbus sampai mendidih kemudian masukkan gula pasir dengan perbandingan gula pasir: sari rimpang $=2: 1$. Melakukan pengadukan sampai gula terlarut sempurna, kemudian sari rimpang berubah menjadi tepung, matikan api dan pengadukan dilakukan terus menerus kemudian dilakukan pengayakan. Setelah dingin jahe instan siap dikemas dan dilakukan pelabelan.

\section{b. Pembuatan Jahe Merah Simplisia}

Simplisia adalah bahan alami yang digunakan sebagai bahan baku obat yang belum mengalami pengolahan tetapi sudah dikeringkan (Ditjen POM 1982 dalam Sembiring, S.B., Yuliani. S. 2013). Pengeringan merupakan proses pengurangan kadar air sampai batas yang terbaik sekitar 8-10\%; karena pada tingkat kadar air tersebut, kemungkinan bahan cukup aman terhadap pencemaran, baik yang disebabkan oleh jamur ataupun insektisida.

Proses Pembuatan Simplisia pada Prinsipnya Meliputi Tahap-Tahap:

- Pada tahap awal rimpang dicuci kemudian pemotongan, rimpang diiris-iris dengan ketebalan 1-2 mm. Pengeringan, penjemuran digunakan nyiru kemudian nyiru yang terisi simplisia ditutup menggunakan sehelai kain hitam dan bagian bawah nyiru kita beri dua buah ganjal balok kayu. Berdasarkan pengalaman dibutuhkan waktu \pm 5 hari. Pengemasan, dilakukan setelah simplisia dingin.

\section{c. Pembuatan Jahe Merah Bubuk}

Bahan jahe kering sempurna/simplisia (kadar air sekitar 8-10\%). Bahan tersebut kemudian digiling halus dengan blender, selanjutnya diayak kemudian dikemas.

\section{Prosedur kerja Pengolahan Umbi Bawang Dayak adalah} sebagai berikut:

\section{a. Cara Pembuatan Bawang Dayak Instan}

Bawang dayak dipotong akar dan daunnya, dicuci, diiris, ditambah air $1: 2 \mathrm{~b} / \mathrm{v}$ (1 kg bawang dayak ditambah dengan 2 liter air), diblender, disaring dengan kain blacu, dimasak sampai mendidih sambil diaduk-aduk, ditambahkan gula 1: $1 \mathrm{~b} / \mathrm{b}$ (1 kg bawang dayak, $1 \mathrm{~kg}$ gula pasir), aduk terus sampai membentuk kristal, dinginkan, jika ukuran butiran besar, haluskan dengan blender, kemudian disaring, dan tahap akhir dikemas.

\section{b. Pembuatan Bawang Dayak Simplisia}

Cara pembuatan simplisia bawang dayak sebagai berikut :Bawang dayak dicuci, dipotong akar dan daunnya, diiris dengan ketebalan 1 - 2 mm, selanjutnya dikeringkan. Proses pengeringan sama dengan pembuatan jahe merah simplisia.

\section{c. Pembuatan Bawang Dayak Bubuk}

Pembuatan bawang dayak bubuk, bahan yang digunakan adalah bawang dayak kering /simplisia (kadar air sekitar 8-10 \%). Bahan tersebut kemudian digiling halus dengan blender, selanjutnya diayak/disaring, dan dikemas dalam wadah yang kering.

Dalam pelaksanaan penyuluhan dan pelatihan acara berjalan lancar tidak ada kendala semua peserta merespons positif, dapat terlihat mereka antusias mendengarkan penjelasan dan beberapa orang bertanya aktif dan mengeluarkan pendapat. Kelompok ibu-ibu ini lebih terbuka wawasannya bahwa rimpang jahe dan umbi bawang dayak dapat diolah menjadi simplisia, bubuk, dan instan.

Sebelum diberi pelatihan peserta belum banyak mengetahui cara mengolah tanaman obat tradisional. Ada beberapa orang yang pernah mencoba mengolah jahe hanya dikeprok dan ditambah gula aren kemudian diseduh air hangat dan langsung diminum, demikian juga dengan umbi bawang dayak dirajang kemudian diseduh dengan air hangat kemudian langsung diminum, tetapi cara tersebut katanya kurang praktis sehingga tidak rutin dapat mengerjakannya. Diharapkan peserta pelatihan dapat memanfaatkan pengetahuan ini untuk lebih mengoptimalkan, mengimplementasikan, dan dapat dijadikan usaha untuk menambah pendapatan rumah tangga. Setelah pelaksanaan pelatihan pengolahan tanaman obat tradisional berupa simplisia, bubuk, dan instan nampak peningkatan pengetahuan. 
Semua peserta pelatihan terlibat dalam pelaksanaan pelatihan,mulai dari membersihkan bahan, merajang, memblender, memasak sampai mengemas. Semua peserta berminat untuk mencoba dirumahnya masing-masing, karena untuk mendapatkan bahan baku sangat mudah baik itu dari tanaman sekitar rumah maupun membeli di pasar tradisional dan harganya terjangkau.

Dalam pelatihan ini dijelaskan pula model-model kemasan yang lebih menarik dan modern sehingga menarik minat orang apabila dijual. Ternyata cara tersebut membuahkan hasil yang baik setelah Tim Pelaksana mempublikasikan melalui Media Sosial banyak yang berminat membelinya.

Selama pedampingan dan evaluasi peserta sudah mulai mencoba mengolah simplisia dan bubuk dirumah

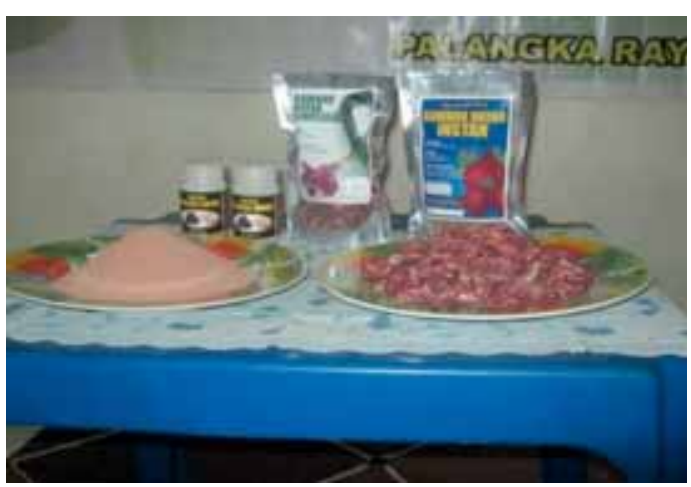

Gambar 1. Simplisia dan Bubuk masing-masing tetapi dengan skala kecil dan cukup untuk keperluan keluarga masing-masing. Ada kendala dalam pengeringan karena pada bulan tersebut sudah musim hujan dan Tim Pelaksana selalu mengingatkan agar bahan tersebut dijaga kehigienisannya.

\section{PENUTUP}

\section{Kesimpulan}

Kedua kelompok Mitra antusias mengikuti pelatihan, mereka memperoleh manfaat, meningkatnya pengetahuan, ketrampilan dan mampu mengolah tanaman obat tradisional (Jahe dan bawang dayak) berupa simplisia, bubuk, dan instan

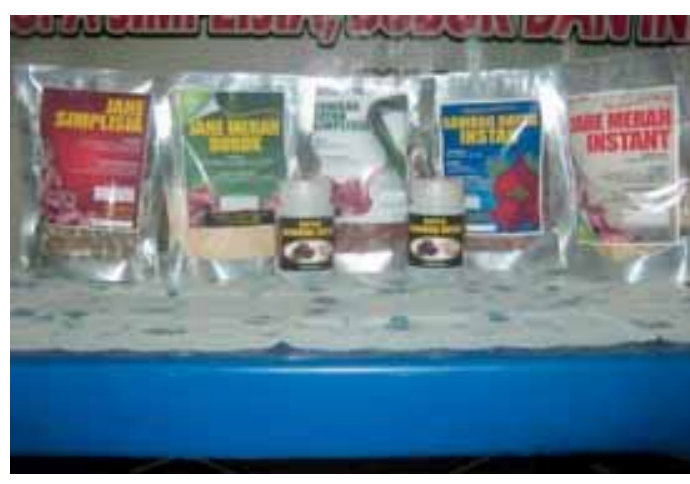

Gambar 2. Contoh Kemasan dan Label

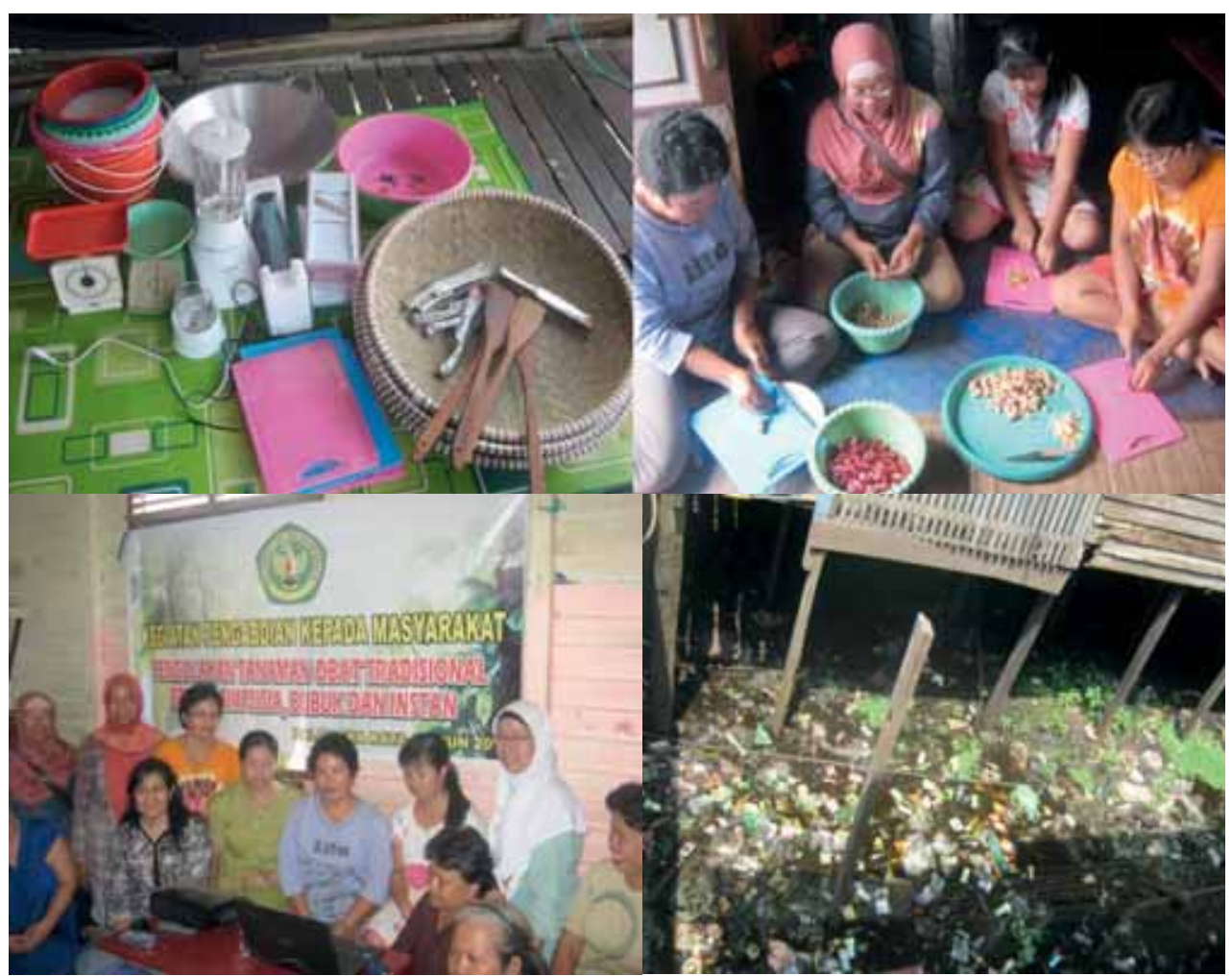

Gambar 3. Dokumentasi Kegiatan Pengolahan Tanaman Obat Tradisional Berupa Simplisia, Bubuk, dan Instan 
dan cara pengemasan . Pelatihan pengolahan tanaman obat tradisional berupa simplisia, bubuk, dan instan dan cara pengemasan ditujukan untuk membuka wawasan Mitra bahwa tanaman obat bisa diolah dan dikemas secara praktis dan dikonsumsi secara instan namun tetap sehat dan aman.

\section{Saran}

a. Perlunya dilakukan pembinaan dan pendampingan bagi ibu-ibu kelompok Mitra dan diberi motivasi agar mereka mau mengembangkan dalam skala yang lebih besar sehingga dapat dijadikan usaha atau home industri dengan pengemasan yang lebih modern sehingga bisa bernilai jual yang lebih tinggi dan berkelanjutan.

b. Agar tetap mempertahankan kearifan lokal berupa budaya melestarikan dan memanfaatkan tanaman obat tradisional dan dapat mengembangkan produk minuman instan atau bubuk murni agar menjadi bentuk produk yang layak dipasarkan.

\section{DAFTAR PUSTAKA}

Badan Penelitian dan Pengembangan Kesehatan. 2014. Riset Saintifikasi Jamu. Kementerian Kesehatan RI. www.litbang.depkes.go.id/Diakses 03 Juni 2014.

CV. D\&D Indonesia, 2013. Model-model Kemasan. www. kemasanUKM.com. diakses 13 April 2014.

Galingging, R.Y., 2013. Bawang Dayak (Eleutherinepalmifolia) Sebagai Tanaman Obat Multifungsi. BPTP Kalimantan Tengah. kalteng.litbang.deptan.go.id/. Diakses 2 Juni 2013.

Hernani dan Winarti,C. 2013. Kandungan Bahan Aktif Jahe dan Pemanfaatannya dalam Bidang Kesehatan. Status Teknologi Hasil Penelitian Jahe hal.125-142.

Balai Besar Penelitian dan Pengembangan Pascapanen Pertanian. http://www.litbang.deptan.go.id. Diakses 12 April 2014.

Sembiring, S.B., dan Yuliani. S. 2013. Penanganan dan Pengolahan Rimpang Jahe. Status Teknologi Hasil Penelitian Jahe hal. 111-124. Balai Penelitian Tanaman Rempah dan Obat (Balittro). Bogor. http://www.litbang. deptan.go.id. Diakses 12 April 2014. 